\title{
THE CONTEMPORARY MALE DEFAULTER
}

\author{
BY \\ GORDON O. HORNE \\ Director, Department of Venereal Diseases, General Infirmary, Leeds
}

Many studies have been made in the past of patients defaulting from venereal diseases clinics. Some of these reports have been purely statistical, and in others the social and other factors influencing default rates have been analysed. This article presents a study of the "contemporary" male defaulter. As modern methods of treatment and the more " enlightened" attitude of the public to venereal diseases may have modified the default pattern and its significance, no excuse is offered for reporting another series. In this instance no review of the literature has been undertaken.

\section{Clinical Material}

The material selected for study is taken principally from the records of the male venereal diseases clinic at Edinburgh, from January, 1948, to March, 1950. During this period both the medical and nursing staff, and the schedules of treatment and management of cases, remained constant. The same criteria of default and the same system of tracing defaulters were employed during the whole period, but these had not been designed with a subsequent analysis of results in view. In other words, this was not a planned experiment. The investigation is not claimed to be a complete review, and certain groups of patients have been selected in order to illustrate various points.

The principal deductions are made from the behaviour of male patients with early (primary and secondary) syphilis who were diagnosed and whose treatment started at the clinic between January 1, 1948, and December 31, 1949. It is necessary to indicate briefly the management of these patients. They were all prescribed a course of penicillin, ranging from 5 to 12 mega-units (the dose depending on the stage of the disease when treatment started) together with one or two " unit" courses of arsenic and bismuth. Those admitted to the ward for initial treatment received penicillin 3-hourly, and were discharged when the course was completed. Those treated from the beginning as out-patients reported daily for penicillin (oil-wax or procaine), the number of attendances ranging from eight to twenty. Reinforcement with arsenic and bismuth was started a few days after the first injection of penicillin. A " unit" course consisted of twice-weekly intravenous mapharside and intramuscular bismuth for 10 weeks. One or two unit courses were given, depending on the stage of the disease

TABLE I

EARLY SYPHILIS, DEFAULT RATE BY STAGE OF DISEASE AND MODE OF TREATMENT

\begin{tabular}{|c|c|c|c|c|c|c|c|c|}
\hline \multirow{4}{*}{$\begin{array}{l}\text { Mode of Initial } \\
\text { Treatment }\end{array}$} & \multirow{4}{*}{$\begin{array}{l}\text { Stage of } \\
\text { Disease }\end{array}$} & \multicolumn{6}{|c|}{ Time of Default } & \multirow{4}{*}{$\begin{array}{c}\text { Total } \\
\text { Default } \\
\text { Rate } \%\end{array}$} \\
\hline & & \multicolumn{3}{|c|}{$\begin{array}{l}\text { Before End of First } \\
\text { Course }\end{array}$} & \multicolumn{3}{|c|}{$\begin{array}{l}\text { Between First and End } \\
\text { of Second Course }\end{array}$} & \\
\hline & & \multirow{2}{*}{$\begin{array}{l}\text { Total } \\
\text { Cases }\end{array}$} & \multicolumn{2}{|c|}{ Defaulters } & \multirow{2}{*}{$\begin{array}{l}\text { Total } \\
\text { Cases }\end{array}$} & \multicolumn{2}{|c|}{ Defaulters } & \\
\hline & & & No. & Rate \% & & No. & Rate \% & \\
\hline \multirow{2}{*}{$\begin{array}{l}\text { All treatment as } \\
\text { out-patient }\end{array}$} & Primary & 72 & 12 & 17 & 14 & 3 & 21 & 21 \\
\hline & Secondary & 17 & 3 & 18 & 14 & 2 & 14 & 29 \\
\hline \multirow{2}{*}{$\begin{array}{l}\text { Penicillin as in- } \\
\text { patient, remainder } \\
\text { as out-patient }\end{array}$} & Primary & 26 & 5 & 19 & 6 & 1 & 17 & 26 \\
\hline & Secondary & 46 & 9 & 20 & 36 & 5 & 14 & 31 \\
\hline Total $\ldots$ & . & 161 & 29 & 17 & 70 & 11 & 16 & 25 \\
\hline
\end{tabular}


and on the blood serology before treatment and after the first course. A rest of four weeks was always given between courses, during which period the patient did not attend the clinic.

Action was taken whenever a patient was two to three days overdue for an injection of penicillin, or seven to ten days overdue in the arsenic and bismuth course. The principal method used to obtain the return of defaulters was a stereotyped letter, followed, if this failed, by a more personal letter. Other efforts used in some cases included approaches through the patient's wife, if she were also attending, and through his doctor, and in a few cases by personal visitation. On each occasion that a defaulting patient returned to the clinic he was specially interviewed, and the importance of continuation of treatment stressed, the approach being adapted to the individual patient. No action was taken when patients defaulted after completing one unit course.

During the period under review 242 patients started treatment, but only those who remained under supervision at the clinic until the end of their prescribed course, or until they defaulted, have been considered. This excluded a large number who were transferred to other clinics at various stages of treatment. Two patients whose unit course was suspended on account of intolerance to the drugs have also been omitted, and the number remaining is 161 . The distribution of primary and secondary cases, and of out-patients and in-patients is shown in Table I. Minor modifications in treatment schedules are inevitable in individual cases, but this series was remarkable for its constancy in this respect. In two cases treatment was interrupted on account of intolerance to arsenic, and was continued with weekly injections of bismuth.

\section{Summary of Default Rate and Pattern}

It is of value to consider the default rate up to the end of the first unit course (after which there was an interval of four weeks before the second course was started), and up to the end of the prescribed treatment, whether this was one or two courses.

Strictly speaking, a defaulter was anyone who was overdue for an injection according to the standards laid down in the last section. In seven cases, however, a note was made (at the time of the patients' return to the clinic) that there had been a justifiable reason for default, and that the return was probably not attributable to the receipt of a prompting letter. For the purpose of this analysis these patients have not been labelled " defaulters". One of the thirty patients who defaulted before the end of the first unit course eventually completed his course after several attempts, and he has also been omitted. As none of the other 29 ever did complete their treatment, and as no action was taken when default occurred after the end of the first unit course, a "defaulter" in the statistical analysis means a patient who never completed his prescribed treatment.
Of the 161 patients, four failed to complete the penicillin course and another 25 failed to complete the first unit course (default rate 17 per cent.). Seventy were recommended a second course, but of these four failed to return after the rest period, and seven defaulted before the end of the second course (default rate 16 per cent.). The total default rate up to the end of treatment (40 in 161) was 25 per cent.

Fifteen of the 29 who defaulted before the end of the first unit course failed to return to the clinic, but only two of them had not already completed a course of penicillin. Another fifteen were persuaded to return, but all soon defaulted again, and two of them never completed even the penicillin treatment. Six of these were persuaded to return again, and all defaulted again. Three of the six returned, but two defaulted again, and the third was the only one of the original thirty defaulters ever to complete the unit course (he is not counted as a defaulter in the analysis in Table I).

Criticism may be levelled at the low return rate of defaulters ( 50 per cent. or less in each group), and at the inadequate measures adopted to trace them, but it will be seen what little benefit resulted even from the efforts that were made : two men eventually completed a course of penicillin, but only one the whole course of treatment. The small amounts of treatment administered during their short attendances between defaults were unlikely to have influenced the rate of cure. Only four out of 161 , however, failed to complete a course of penicillin.

The inevitable conclusion that the patients in the group would either complete their treatment or would not, irrespective of any steps taken to influence them, was supported by another observation. In the seven cases in which letters were sent in the usual way when default occurred, but the return was considered to be spontaneous and not related to the receipt of a prompting letter, treatment was completed without further interruption.

\section{Further Observations on the Group}

A more detailed analysis of the group was made in order to try to discover any factors that might have influenced the default rate (Tables I, II, and III).

Stage of Disease.-It might have been thought, for example, that those who waited until the development of the signs and symptoms of secondary syphilis before seeking medical advice, would prove less satisfactory patients than those who reported soon after the appearance of a primary sore. The default rate at the end of the first course was exactly the same in both primary and secondary groups, and 
TABLE II

EARLY SYPHILIS DEFAULT RATE BY MARITAL STATE, AGE GROUP, AND OCCUPATION

\begin{tabular}{|c|c|c|c|c|c|c|c|c|}
\hline & \multirow{4}{*}{ Group } & \multicolumn{6}{|c|}{ Time of Default } & \multirow{4}{*}{$\begin{array}{l}\text { Total } \\
\text { Default } \\
\text { Rate \% }\end{array}$} \\
\hline & & \multicolumn{3}{|c|}{$\begin{array}{c}\text { Before End of First } \\
\text { Course }\end{array}$} & \multicolumn{3}{|c|}{$\begin{array}{l}\text { Between First and End } \\
\text { of Second Course }\end{array}$} & \\
\hline & & \multirow{2}{*}{$\begin{array}{l}\text { Total } \\
\text { Cases }\end{array}$} & \multicolumn{2}{|c|}{ Defaulters } & \multirow{2}{*}{$\begin{array}{l}\text { Total } \\
\text { Cases }\end{array}$} & \multicolumn{2}{|c|}{ Defaulters } & \\
\hline & & & No. & Rate \% & & No. & Rate \% & \\
\hline \multirow{3}{*}{$\begin{array}{c}\text { Marital } \\
\text { state* }\end{array}$} & Single & 89 & 15 & 17 & 33 & 7 & 21 & 25 \\
\hline & Married & 53 & 9 & 17 & 30 & 2 & 7 & 21 \\
\hline & $\begin{array}{c}\text { Separated or } \\
\text { divorced }\end{array}$ & 16 & 5 & 31 & 4 & 2 & 50 & 44 \\
\hline $\begin{array}{l}\text { Age } \\
\text { group } \\
\text { (years) }\end{array}$ & $\begin{array}{c}<19 \\
20-24 \\
25-29 \\
30+\end{array}$ & $\begin{array}{r}3 \\
34 \\
44 \\
80\end{array}$ & $\begin{array}{r}0 \\
8 \\
9 \\
12\end{array}$ & $\begin{array}{r}0 \\
24 \\
20 \\
15\end{array}$ & $\begin{array}{r}1 \\
10 \\
19 \\
40\end{array}$ & $\begin{array}{l}0 \\
4 \\
4 \\
3\end{array}$ & $\begin{array}{r}0 \\
40 \\
21 \\
8\end{array}$ & $\begin{array}{r}0 \\
35 \\
30 \\
19\end{array}$ \\
\hline \multirow{6}{*}{ Occupation } & $\begin{array}{l}\text { Superior trades, } \\
\text { miners }\end{array}$ & 62 & 6 & 10 & - & - & - & - \\
\hline & $\begin{array}{c}\text { White collar " } \\
\text { employment }\end{array}$ & 13 & 3 & 23 & 一 & - & - & - \\
\hline & $\begin{array}{c}\text { Inferior trades, } \\
\text { labourers, drivers }\end{array}$ & 70 & 18 & 25 & - & - & - & - \\
\hline & $\begin{array}{c}\text { Seamen (merchant } \\
\text { navy and trawler } \\
\text { men) }\end{array}$ & 11 & 0 & 0 & - & - & - & - \\
\hline & Unemployed & 2 & 1 & - & - & - & - & - \\
\hline & Unknown & 3 & 1 & - & - & - & - & - \\
\hline
\end{tabular}

the total default rate in the primary cases was not significantly lower (Table I).

Admission to Hospital for Initial Treatment.It might also have been thought that there would be a difference between the "out-patient" and "in-patient" groups. In those who received penicillin in the ward, practically all the signs and symptoms of syphilis had disappeared before they were discharged and called on to report regularly for treatment as out-patients, whereas those who were treated from the beginning as out-patients had already established an "attendance habit" before being free of signs and symptoms. There was, however, no significant difference between the two groups (Table I). The criteria for admission to hospital were too complicated to warrant an analysis with a view to determining whether the element of selection involved might have influenced the deductions.
Marital State.-It might be supposed that married men would be more anxious to complete their treatment than single men, but the default rate in the two series was exactly the same at the end of the first course, and not significantly different to the end of the prescribed treatment. The default rate was, however, considerably higher among the small group of men who stated that they were separated from their wives, or divorced (Table II).

Age.-The maximum default rate occurred in the 20 to 24 age group, and decreased with increasing age. The few patients under the age of 20 did not default (Table II).

History of Previous Venereal Disease.-Approximately one-third of the patients admitted to having had a venereal disease before, and the default rate in this group was exactly the same as among those who did not admit previous venereal disease (Table III). Twenty-four patients who admitted to having 
had syphilis previously were proportionately distributed between the defaulters and non-defaulters.

TABLE JII

EARLY SYPHILIS, DEFAULT RATE BY PREVIOUS HISTORY OF VENEREAL DISEASE

\begin{tabular}{lcccc}
\hline $\begin{array}{c}\text { Previous Venereal } \\
\text { Disease }\end{array}$ & $\begin{array}{c}\text { No. of } \\
\text { Cases }\end{array}$ & Dofaulters \\
\hline Admitted .. & $\ldots$ & 51 & 8 & Rate \% \\
Not admitted & $\ldots$ & 109 & 21 & 18 \\
Unknown & $\ldots$ & 1 & 0 & - \\
\hline
\end{tabular}

Occupation.-The only analysis in which the default pattern at least partly coincided with conjecture was that of occupation (Table II). An arbitrary subdivision of 158 patients whose occupation was known showed a lower default rate amongst miners, and others whose occupations called for perseverance and a reasonable standard of intellect, than among those following less exacting occupations, such as drivers and labourers. The default rate was high in the "white collar" group, but the numbers are too small for interpretation. Here the three defaulters were a surveyor, a grocer, and a "cycle agent", and it is doubtful whether the last-named was eligible for this category. There were no defaulters among eleven seamen (Merchant Navy and trawlermen), all of whom had agreed to remain ashore until their treatment was completed.

\section{Other Groups of Patients}

The conclusion that patients with early syphilis were apparently from the beginning either defaulters or not, and could not be influenced in this respect, prompted a similar study of other groups of patients observed during the same period.

Patients with Early Latent Syphilis. - In a series of 24 cases of this type diagnosed in 1948, in which the prescribed treatment was three courses of arsenic and bismuth, following 10 to 12 mega-units of penicillin, nine defaulted before the end of treatment. Two defaulted during penicillin therapy, three during the first course, three during the second, and one after the second course. In spite of several attempts, no patient who once defaulted ever completed the whole treatment, though two completed one course between defaults. The pattern of default here was identical with that of the early syphilis series, and the amount of treatment received between detaults was again unlikely to have influenced the cure rate to any appreciable extent.

Patients under Observation after Risk of Contracting Venereal Disease. - An analysis was also made of all the men who reported to the clinic between
March 16, 1948, and March 15, 1949, with a history of exposure to the risk of contracting venereal disease, but in whom no clinical or serological evidence of this was found, and for whom no treatment of any kind was prescribed. In every case the patient was recommended to remain under observation at the clinic for a total period of three months from the date of exposure, attending weekly during the first two to three weeks, and monthly thereafter. The series was confined to those who still required four or more weeks' observation after their first examination.

It might have been thought that married men who had run the risk of contracting venereal disease outside marriage would have been more anxious to complete observation, but their default rate was as high as that of single men (Table IV). The group of married men separated from their wives, or divorced, is small, but shows a significantly higher default rate. A further subdivision of the married men according to whether they admitted having had intercourse with their wives after extra-marital intercourse (i.e. where the risk to the wife was greater) or not, again showed that this factor did not influence the default rate (Table IV $(a)$ and $(b)$ ).

The group was further subdivided into those to whom the importance of attending for observation was particularly emphasized at the initial interview, and those to whom this very positive approach was not made. Analysis showed that the special exhortation had no effect in reducing the default rate (Table V).

Patients under Observation after Treatment for Gonorrhoea.-This confirmation of the apparent inability of personal influence to control the default rate prompted a further analysis. During the two years under review several new preparations of penicillin were under trial for the treatment of gonorrhoea, and in each of these series an effort was made to select "suitable" patients (i.e. those who would be expected to cooperate and to attend for tests of cure and until observation was completed). Table VI shows that the default rate before the end of observation in the "selected" series was as high as that in the " unselected" series. In a trial series in which oral penicillin was used particular care was taken in the selection of cases, but the default rate in this group was not significantly lower. Again, all the patients were apparently either defaulters or not, and were not amenable in this respect to such influences as were applied. Nor was it easy to forecast into which group any patient would fall.

During 1948 and 1949, 198 letters were sent to 175 patients with acute gonorrhoea who defaulted 
before the end of observation after treatment with one injection of penicillin. Of these letters, 32 were returned by the Post Office labelled "incorrect address" or "gone away". The receipt of a letter prompted 46 of the patients to return, but only 12 of these completed observation before defaulting again. Two of these second-defaulters were again persuaded to return, but both defaulted again, and no further action was taken. Here again the default pattern was the same, though not quite so universal as in the early syphilis series.

\section{Collateral Series from Leeds Clinic}

Analysis was purposely made of cases from the Edinburgh clinic during a period when most of the possible influencing factors, such as medical staff and method of management of the patients, were constant. However, during 1947, when these two factors were somewhat different (for example, out-patient attendance for penicillin fluctuated according to different preparations in use, some patients were treated with a 26-weeks' continuous course of arsenic and bismuth, and a different policy with regard to tracing defaulters was used) the default pattern was exactly the same. Eight of the forty defaulters returned, but none of these ever completed treatment, although one made four further attempts, and another two.

Similar samples were analysed from the venereal diseases department at Leeds, where, of course,

TABLE IV

OBSERVATION AFTER EXPOSURE TO RISK, DEFAULT RATE BY MARITAL STATE (EDINBURGH AND LEEDS)

\begin{tabular}{|c|c|c|c|c|c|c|c|c|c|}
\hline & & & & \multicolumn{3}{|c|}{ Edinburgh } & \multicolumn{3}{|c|}{ Leeds } \\
\hline \multirow{2}{*}{\multicolumn{4}{|c|}{ Marital State }} & \multirow{2}{*}{$\begin{array}{l}\text { Total } \\
\text { Cases }\end{array}$} & \multicolumn{2}{|c|}{ Defaulters } & \multirow{2}{*}{$\begin{array}{l}\text { Total } \\
\text { Cases }\end{array}$} & \multicolumn{2}{|c|}{ Defaulters } \\
\hline & & & & & No. & Rate $\%$ & & No. & Rate $\%$ \\
\hline Single & . & . & . & 130 & 67 & 52 & 92 & 46 & 50 \\
\hline & (a) & . & $\cdots$ & 37 & 20 & 54 & 11 & 6 & 55 \\
\hline Married & (b) & . & . & 61 & 35 & 57 & 66 & 35 & 53 \\
\hline & Tot & . & $\cdots$ & 98 & 55 & 56 & 77 & 41 & 53 \\
\hline Separatec & Dive & ed & . & 10 & 9 & 90 & 11 & 8 & 73 \\
\hline & Tot & . & $\cdots$ & 238 & 131 & 55 & 183 & 96 & 52 \\
\hline
\end{tabular}

(a) Marital intercourse admitted after extra-marital.

(b) Marital intercourse not admitted after extra-marital.

TABLE V

OBSERVATION AFTER EXPOSURE TO RISK, DEFAULT RATE BY DEGREE OF EXHORTATION (EDINBURGH)

\begin{tabular}{|c|c|c|c|c|c|c|c|c|c|}
\hline & & & & \multicolumn{3}{|c|}{ Specially Exhorted } & \multicolumn{3}{|c|}{ Not Specially Exhorted } \\
\hline \multirow{2}{*}{\multicolumn{4}{|c|}{ Marital State }} & \multirow{2}{*}{$\begin{array}{l}\text { Total } \\
\text { Cases }\end{array}$} & \multicolumn{2}{|c|}{ Defaulters } & \multirow{2}{*}{$\begin{array}{l}\text { Total } \\
\text { Cases }\end{array}$} & \multicolumn{2}{|c|}{ Defaulters } \\
\hline & & & & & No. & Rate \% & & No. & Rate \% \\
\hline Single & $\cdots$ & . & . & 37 & 16 & 43 & 93 & 51 & 55 \\
\hline & (a) & $\cdots$ & . & 21 & 12 & 57 & 40 & 23 & 58 \\
\hline Married & (b) & $\cdots$ & $\ldots$ & 12 & 6 & 50 & 25 & 14 & 56 \\
\hline & Tot & . & $\ldots$ & 33 & 18 & 55 & 65 & 37 & 57 \\
\hline Separate & Dive & & $\cdots$ & 3 & 3 & 100 & 7 & 6 & 86 \\
\hline & Tota & $\ldots$ & $\ldots$ & 73 & 37 & 51 & 165 & 94 & 56 \\
\hline
\end{tabular}

(a) Marital intercourse admitted after extra-marital.

(b) Marital intercourse not admitted after extra-marital. 
TABLE VI

GONORRHOEA, DEFAULT RATE BY "SELECTED" AND “UNSELECTED" SERIES

\begin{tabular}{|c|c|c|c|c|}
\hline Series & Treatment & No. of Cases & $\begin{array}{l}\text { No. who } \\
\text { completed } \\
\text { Course of } \\
\text { Observation }\end{array}$ & Default Rate $\%$ \\
\hline Unselected & Eight standard preparations of penicillin & 348 & 150 & 57 \\
\hline \multirow{3}{*}{ Selected } & Five trial preparations of penicillin & 106 & 51 & 52 \\
\hline & Oral penicillin & 48 & 25 & 48 \\
\hline & Total & 154 & 76 & 51 \\
\hline
\end{tabular}

there was a different staff and where different methods were used. Cases of early syphilis were treated with either a 26-weeks' course, or unit courses, of arsenic and bismuth in addition to penicillin.

All 52 cases, male and female, who started treatment for early syphilis during 1949 and remained under supervision at the clinic until the completion of treatment or until default, followed exactly the same pattern as at Edinburgh. A more elaborate system was used for tracing defaulters than at Edinburgh, and a higher proportion of them returned on several occasions, but in no instance did a patient who had once defaulted complete the prescribed course of treatment, and again the few injections received during their short periods of attendance were unlikely to have influenced the ultimate cure rate. Here again, in all cases where the initial default was considered to be justifiable, and the patient's return not directly due to the receipt of a "defaulter" letter, treatment was completed without further interruption.

At Leeds, an exactly comparable series of men who reported after exposure to the risk of contracting venereal disease, and were advised to remain under observation for three months, has been analysed (Table IV). The default rate is strikingly similar in numbers to the Edinburgh series, and follows exactly the same pattern.

\section{Deductions}

The numbers in the series analysed are small, and are rendered smaller by the necessary subdivision, so care must be used in drawing conclusions. Nevertheless, it is claimed that the careful study of a small series such as this can be as profitable as that of some larger series where possible influencing factors are more difficult to control. It should also be noted that the conclusions are based on a study of male patients. Different problems may arise with regard to female patients, although in the series of cases of early syphilis at Leeds, the default pattern of the female was exactly the same as that of the male.

It appears to be difficult to forecast if a patient will default, whether he be required to attend regularly for treatment, to attend for observation after treatment, or simply to attend for observation, although each group has its own default rate. The tendency to default appears to be less in the more stable and more intellectual (judged by marital history and occupation), and may diminish with increasing age. Regular attendance is rare when default has once occurred, and this default pattern cannot be influenced. It may be that the obsessional tendencies usually dreaded by venereologists have a critical beneficial influence on this aspect of behaviour.

\section{Discussion}

Patients with Early Latent Syphilis.-If it be assumed that 75 per cent. of the patients receiving the course of penicillin prescribed for early syphilis were cured (probably a low estimate), then 25 per cent. of the 26 at Edinburgh who received little treatment in addition to penicillin were not cured. That is, probably six or seven patients out of 161 were not cured, and if no attempt had been made to trace patients defaulting after the end of the course of penicillin, there would only have been one more left uncured. In the series at Leeds, there would have been no difference at all. While obviously no effort should be spared to ensure that a patient with primary or secondary syphilis receives an adequate course of penicillin, if only to render him non-infectious, it is doubtful if it is worth expending much effort when default occurs at a later stage of treatment. Probably one letter, drawing attention to the implications of default, would discharge the responsibilities to the patient and the community.

If a patient returns after default, the knowledge that he will most probably default again in a short 
time suggests that he should immediately be given a second concentrated course of penicillin in order to produce the best possible therapeutic effect rather than continue the arsenic and bismuth. The ultimate result as regards cure of such a procedure, compared to the use of more prolonged arsenic and bismuth therapy (still supported by most syphilologists in this country), has yet to be assessed, but it might be wise in the circumstances.

In view of the fact that a number of patients default when given a period of rest from injections at the end of a 10-weeks' course, it might be advisable, when more prolonged treatment is required, to use an uninterrupted schedule. Study of cases on a 26-weeks' schedule, however, suggests that there is a cumulative default rate over a period of time, which is probably uninfluenced by a respite from injections.

It is appreciated that just as important in the management of a patient with early syphilis is the tracing and treatment of the consort and any others possibly infected, and it may be considered desirable to trace a defaulter solely with this end in view. In both the Edinburgh and Leeds series, however, on no occasion was a consort ever traced subsequent to a defaulter returning. (This also applied to the series of gonorrhoea defaulters.) It would appear that if a consort is not traced before default occurs, she is unlikely ever to be traced.

There may be occasions when this attitude of apparent indifference to defaulters requires to be modified, especially when husband and wife are both involved, but at Edinburgh there were several cases of this type where all efforts to get one or other to attend regularly completely failed, and in some cases both had to be abandoned.

Patients under Observation after Exposure to Risk of Contracting Venereal Disease.-It is doubtful if any useful purpose is served by attempting to trace defaulters of this type, especially in areas where there is a very low rate of infectious syphilis, unless the consort is known to be infected and there is a heavy risk to the patient, or unless there are some suspicious clinical signs. At Edinburgh no action was taken in these cases when default occurred, and so their ultimate fate is unknown, but in none of those who completed observation did the Wassermann reaction become positive.

The desirability of sending a prompting letter, or of taking more active steps, in such cases is questionable. The risk of precipitating domestic upheaval as a result of information leaking out has always to be weighed against the risk of concealed infection occurring.

\section{VENEREAL DISEASES}

Patients under Observation after Treatment for Gonorrhoea.-Some divergence of opinion still exists on the efficiency of penicillin in the treatment of gonorrhoea, and views on the desirability of tracing patients who default before test of cure will vary according to the degree of faith in penicillin. It can be argued that if a patient has a clinical relapse he will return to the clinic of his own accord. At Edinburgh no defaulter who returned as a result of receiving a letter was found to have clinical evidence of gonorrhoea, and bacteriological tests of cure completed on about half were all satisfactory.

Even more debatable is the desirability of ensuring serological observation from the point of view of syphilis in all cases of gonorrhoea treated with penicillin. Only a small proportion of patients nowadays remain under observation for the recommended observation period of four to six months. During 1948 and 1949, of approximately 950 cases of gonorrhoea, not one was found to develop a positive blood Wassermann reaction during observation after treatment of gonorrhoea (including returned defaulters) in the absence of clinical evidence of syphilis.

If a realistic attitude be adopted, the management of such cases will also be influenced by the appreciation of the fact that a high proportion of the patients are habitually promiscuous. For example, in the " specially selected" series of cases of gonorrhoea, 7 per cent. contracted a new infection, and many more admitted exposure to the risk during observation. In no instance in the whole series of gonorrhoea cases was a consort traced as a result of a defaulter's being persuaded to return. Again, one letter would appear to discharge the responsibilities to the patient and the community.

\section{Conclusion}

A plea is therefore made for an assessment of what constitutes a " defaulter " under contemporary conditions, and what steps should be taken when default occurs. It is important that almoners and other auxiliary services attached to venereal diseases clinics should have the opportunity of giving the maximum service to the patients and the community. Wastage of effort should be avoided.

Macfarlane (1949) stàtes that at the Venereal Diseases Department in the Newcastle General Hospital :

\footnotetext{
" the annual incidence of default since 1945 has not shown the over-all improvement which is to be expected with an efficient medico-social unit."

It may be that even an efficient medico-social unit can have little influence on the default rate
} 
although it may achieve excellent results in other ways, but a careful investigation of its work might lead to the discovery of how even more profitable results could be achieved. The evidence in this paper justifies the modern tendency to emphasize "case-finding" rather than "case-holding".

Even if the conclusions presented here (as, for example, that defaulters are little amenable to personal or other influences) are true, it cannot be too strongly impressed that the adoption of an attitude of cynical pessimism is to be condemned. In the face of such realism it is important to preserve an idealistic attitude, and to maintain the highest professional and ethical standards. There is no doubt that the successful handling of all the problems associated with default depends to a great extent on the personality, and especially on the patience, of the medical and social staff. These conclusions should be borne in mind in the event of a re-opening of the controversial subject of notification of venereal disease, with the associated legal measures necessary to control defaulters.
Finally, the disheartening pattern of behaviour exhibited here is probably not confined to patients with venereal disease, and investigations are being undertaken to discover whether others with similar obligations discharge them any more efficiently.

The author is indebted to Dr. R. C. L. Batchelor, Director of the Department of Venereal Diseases, Royal Infirmary, Edinburgh, under whose direction he was working during the period reviewed, to the medical and nursing staff of the department for their cooperation, and in particular to Mr. J. McSherry for his enthusiastic clerking assistance. $\mathrm{He}$ is also indebted to Dr. Robert Lees, lately Director of the Department of Venereal Diseases, General Infirmary, Leeds, for permission to analyse the case records during the period reviewed, and to Dr. J. B. Bittiner for carrying out the analysis.

It should be added that Dr. Batchelor and Dr. Lees, as directors of the clinics concerned, do not necessarily agree with the views of the author.

\section{REFERENCE}

Macfarlane, W. V., (1949). "Annual Report of the Venereal Diseases Department, Newcastle General Hospital ". 
TABLE

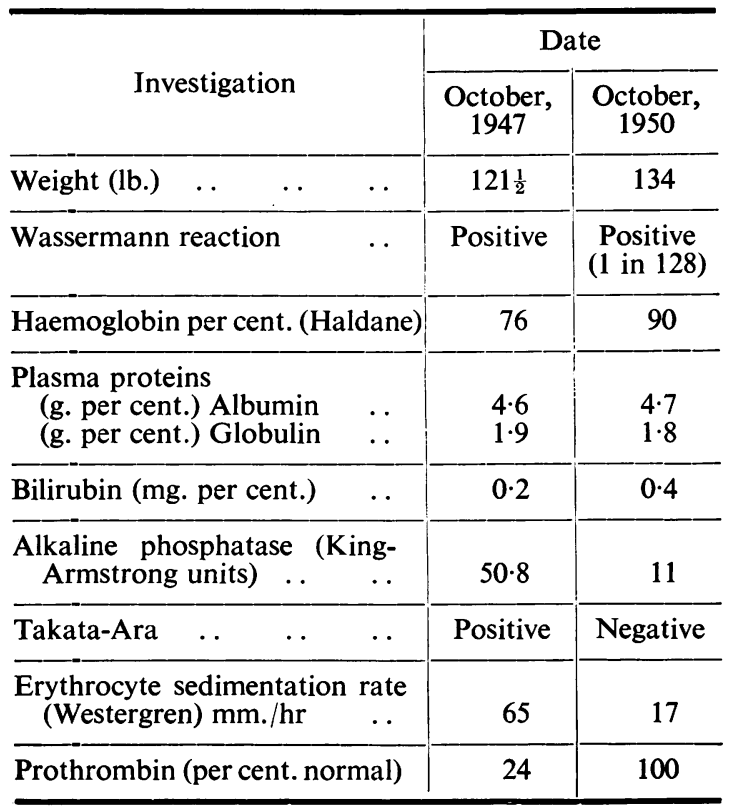

The administration of penicillin without preparation with intramuscular bismuth was deemed necessary in view of the patient's rapid deterioration, and the dramatic response justified this decision.

Three years after treatment was begun, he is fit and working a 9-hour day in a café 6 days a week. There is minimal evidence of liver dysfunction. The spleen however is still enlarged and portal hypertension is present. It is impossible to say whether progressive hepatic deficiency will occur or whether the portal hypertension will increase. As yet there is no evidence of hypersplenism, but this remains a potential hazard.

It seems probable that penicillin treatment of late syphilis of the liver will only be effective when gummatous lesions predominate.

Our thanks are due to Dr. Geoffrey Bourne and to Mr. J. B. Hume for permission to publish this case and to Mr. A. H. Hunt for the record of the portal pressure.

\section{REFERENCE}

Tucker, H. A., and Dexter, D. D. (1946). Arch. intern. Med., 78, 313.

\section{CORRECTION}

In the article "The Contemporary Male Defaulter", by G. O. Horne, which appeared in the December 1950 issue of this Journal, the first sub-heading under Discussion on p. 169 should read :

Patients with Early Syphilis (not Early Latent Syphilis). 